\title{
How valuable is feedback of information on hospital referral patterns?
}

\author{
Paulo de Marco, Caroline Dain, Trevor Lockwood, Martin Roland
}

\begin{abstract}
Objectives-To determine general practitioners' responses to and explanations for variation in rates of referral to hospital and how feedback of data on rates of referral could be used to facilitate practices in auditing their own referral behaviour.

Design-Visits by audit facilitators to general practices after feedback of details of rates of referral to hospital derived from annual reports in general practice.

Setting-92 general practices in East Anglia.

Results-General practitioners judged that access to specialist care, the individual skill of general practitioners, patient demand, and fear of litigation were major determinants of referral behaviour. Because there was widespread scepticism about the accuracy of the data on which the feedback was based and because there is no clear relation between rates of referral and quality of care, it was extremely difficult to encourage doctors to use the feedback as a basis for auditing their own hospital referrals.

Conclusion-If general practitioners are to contribute meaningfully to monitoring future changes in referral patterns it will be essential to develop reliable information systems in which doctors have confidence. Furthermore, audits need to be based on analysis of clinical cases rather than on rates of referral.
\end{abstract}

\section{Introduction}

The wide variation in rates of hospital referral among general practitioners is potentially of clinical and economic importance. ${ }^{2}$ According to the 1990 general practitioner contract general practitioners should return details of their hospital referrals to family health services authorities, who could then feed back comparative data on rates of referral. The purpose of this feedback was to encourage practices, particularly those with unusually high or low rates of referral, to examine critically their own referral patterns. Although there are examples when feedback of information has produced alterations in doctors' behaviour, ${ }^{3}$ it was uncertain how general practitioners would interpret feedback on their practices' referral patterns. Our aims were to determine general practitioners' responses to feedback on their referral patterns and to determine whether they would use this information as a basis for auditing their hospital referrals.

Department of Genera Practice, University of Manchester, Rusholme Health Centre, Manchester M14 5NP

Martin Roland, professor of general practice

Correspondence to: Professor Roland.
In October 1991 three part time audit facilitators (PdeM, CD, TL) were appointed to visit and discuss patterns of referral with 113 practices in Peterborough, Norfolk, and East Suffolk health districts. At the visits the facilitators elicited the doctors' views on their own rates of referral. The meetings were deliberately unstructured to allow doctors to discuss factors which they felt were important determinants of referral behaviour. The facilitator then discussed how the practice could be helped to make constructive use of information on their referral patterns and whether the data could be used as a basis for medical audit.

\section{Results}

There was more than a fourfold variation in overall rates of outpatient referral between practices in each of the health districts. Over a period of six months the facilitators visited 92 out of the 113 selected practices. Widespread scepticism about accuracy of their own and other practices' data seriously limited doctors' perception of the value of the feedback.

The doctors in 89 out of 92 practices visited saw no need to alter their referral behaviour, and when rates were unusually high or low explanations were readily offered, which rarely included the doctors' own clinical behaviour. The reasons given by practices for variation in rates of referral identify several factors which have not previously been emphasised in models of the referral process. ${ }^{7-9}$

REASONS FOR VARIATION

Access to specialist care was perceived to be a major determinant of referral behaviour. There was substantial agreement that long waiting lists made doctors less likely to refer patients to hospital. Doctors in three practices commented that their referrals to particular specialties had increased on the appointment of additional consultants. Comments were also made that easy access to hospital, either because of proximity to a district hospital or because specialists visited a health centre or local cottage hospital, made general practitioners more likely to refer patients. Access to physiotherapy was perceived as being associated with lower referral rates to orthopaedic specialists.

The skill of individual general practitioners was the next most commonly described influence on referral behaviour. For relatively low technology specialties or those for which facilities for investigation were available to general practitioners, such as general medicine or dermatology, doctors with specific skills judged that they had low rates of referral to those specialties. There were, however, exceptions to this view from, for example, doctors who believed that specific skills made them more aware of serious or rare diseases and therefore more likely to refer. In high technology specialties doctors with particular skills sometimes had high rates of referral. For example, one doctor, a clinical assistant in ophthalmology, commented that he referred many patients to himself in hospital so that he 
could have the benefit of examining them with more sophisticated diagnostic equipment. The ability of general practitioners to carry out specific procedures in practice-for example, sigmoidoscopy, joint injection, minor surgery, or spinal manipulation-was judged to have a major effect in reducing referral for these procedures.

Patient demand was commonly mentioned as a factor influencing referral decisions. This was thought to be important particularly in affluent areas, where privately insured patients were more likely to request referral, and areas of economic deprivation, where patients were more likely to demand second opinions. Doctors in several practices mentioned the increasing rate of litigation in medicine.

A previous complaint was a major factor tending to increase referrals, with one general practitioner commenting, "The experience of having a complaint brought against me shattered my clinical confidence, and subsequently I approach every consultation with its potential legal consequences very high in my mind. I tend to refer more and sooner than before."

Practices were asked whether they would use the data for medical audit, and possible ways of auditing referrals were discussed. On the whole, there was little interest in auditing referral behaviour. The facilitators perceived two main reasons for this. Firstly, it was very difficult to engage the doctors in discussion about differences in clinical behaviour on the basis of data which many regarded as seriously inaccurate. Secondly, there was a general lack of acceptance of a link between variation in rates of referral and quality of clinical practice among doctors. Doctors from high referring practices were defensive about their clinical practice, and there was a general feeling that to be a low referrer was a good thing, if only because a low referral rate was likely to protect a practice against unwelcome attention from the family health services authority. Six months after the visit by the facilitators the 30 practices that had expressed intitial interest in further work were contacted by telephone to find out whether they had started any review of their hospital referrals. Only four had sone so.

\section{Discussion}

The context in which feedback was given is an important factor in interpreting the responses reported in this study. Data collection on referrals required by the 1990 contract received low priority in many practices, and the data were widely believed to be of poor quality. Furthermore, in the early 1990s several papers were published which found no clear relation between doctors' rates of referral and the standard of their clinical care ${ }^{10-13}$ As a consequence, doctors visited in this study were defensive about any suggestion that variation in rates of referral might imply differences in clinical standards, and it was extremely difficult to persuade doctors to discuss actual clinical practice or to discuss audit of their own referral decisions. Variation in rates of referral as wide as those found in this study may well indicate important differences in clinical management, but the feedback provided by family health services authorities in association with a single visit by a facilitator was not an effective way to engage doctors in discussion about their clinical behaviour.

Despite these limitations discussion with doctors in the 92 practices visited provided valuable data on some of the possible reasons for variation in rates of referral. Referrals were generally believed to be more common when specialist services were more available, which is consistent with some previous reports. ${ }^{14-17}$ Secondly,

\section{Practice implications}

- General practitioners are now required to give details of their hospital referrals to family health services authorities

- Feedback to general practitioners of comparative rates of hospital referral proved a poor stimulus to auditing clinical cases

- Doctors most commonly identified access to specialist care and the skill of individual general practitioners as factors influencing referral decisions

- Changes in referral patterns will be brought about only by adopting better information systems to base audit on

the comments made by general practitioners provided further insights into their beliefs about the relation between the skill of doctors and their rates of referral. Patient demand and the risk of complaints were also believed to be important factors influencing referral decisions.

If general practitioners are to play a meaningful part in monitoring and interpreting future changes in referral patterns, then the development of information systems in which general practitioners have confidence will be an essential prerequisite. It will also be necessary to base audit around discussion of actual clinical condition $\mathrm{s}^{18}$ rather than rates of referral, which seem to be a sterile basis for discussion.

We thank the general practitioners who took part in this study, particularly for the welcome and courtesy extended to the facilitators who visited their practices. The study was supported by a grant from the East Anglian Health Authority.

1 Wilkin D. Explaining variation in referral rates. In: Roland MO, Coulter A eds. Hospital referrals. Oxford: Oxford University Press, 1992:76-91.

Roland MO. Variations in referral rates of general practitioners: causes and significance. In: Hopkins A, Wallace P, eds. Referrals to medical outpatients. London: Royal College of Physicians and Royal College of Genera Practitioners, 1992:33-42.

3 Mugford M, Banfield P, O'Hanlon M. Effects of feedback of information on clinical practice: a review. $B M \mathcal{F} 1991 ; 303: 398-402$.

4 Moore AT, Roland MO. How much variation in referral rates among general practitioners is due to chance? $B M F 1989 ; 298: 500-2$

5 Roland MO, Bartholomew J, Morrell DC, McDermott A, Paul E. Understanding hospital referral rates: a user's guide. $B M \mathcal{F}^{7}$ 1990;301:98-102.

6 Coulter A, Roland MO, Wilkin D. GP referrals to hospitals. A guide for family health services authorities. Manchester: Centre for Primary Care Research, 1991.

7 Dowie R. General practitioners and consutants: a study of outpatient referrals. London: King Edward's Hospital Fund for London, 1983.

8 Wilkin D, Smith A. Explaining variation in general practitioner referrals to hospital. Fam Pract 1987;4:160-9.

9 Newton J, Hayes V, Hutchison A. Factors influencing general practitioners' referral decisions. Fam Pract 1991;8:308-13.

10 Coulter A, Seagroatt V, McPherson M. Relation between general practices' outpatient referral rates and rates of elective admission to hospital. $B M 7$ outpatient referral
1990;301:273-6.

11 Knottnerus JA, Joosten J, Daams J. Comparing the quality of referrals of general practitioners with high and average referral rates: an independent panel review. British foumal of General Practice 1990;40:178-81.

12 Roland MO. Measuring appropriateness of hospital referrals. In: Roland MO, Coulter A, eds. Hospital referrals. Oxford: Oxford University Press, 1992:136-49.

13 Reynolds GA, Chitnis JG, Roland MO. General practitioner outpatient referrals: do good doctors refer more patients to hospital? $B M \mathcal{f}^{1991 ; 302}$ 1250-2.

14 Roland MO, Morris RJ. Are referrals by general practitioners influenced by the availability of consultants? $B M \mathcal{Y} 1988 ; 297: 599-600$

15 McCormick A, Rosenbaum M. Morbidity statistics from general practice 1981-2. Third national study: socio-economic analyses. London: HMSO, 1990.

16 Madeley RJ, Evans JR, Muir B. The use of routine referral data in the development of clinical audit and management in north Lincolnshire.
dithe development of clinical audit and manage

17 Kennedy F, McConnell B. General practitioner referral patterns. Fournal of Public Health Medicine 1993;15:83-7.

18 Coulter A. Auditing referrals. In: Roland MO, Coulter A, eds. Hospital referrals. Oxford: Oxford University Press, 1992:150-62.

(Accepted 28 September 1993) 